\title{
Correspondence
}

\section{Anaesthesia, atracurium and Duchenne muscular dystrophy}

To the Editor:

A 12-year-old male, weighing $30 \mathrm{~kg}$, confined to a wheelchair because of progressive muscular weakness caused by Duchenne muscular dystrophy (DMD) presented for extensive dental treatment. Previous attempts under local anaesthesia had been unsuccessful because of patient resistance. Preoperative examination revealed marked kyphoscoliosis and fatty infiltration of muscles. The chest examination was normal and there were no signs of cardiac insufficiency. Spirometry unfortunately could not be performed. The chest $x$-ray was normal. The ECG showed tall $R$ waves in $V 1$ and $Q$ waves in V4-6. The resting CPK was $7830 \mathrm{IU} / \mathrm{L}$ (normal range 0-70 IU/L).

Following premedication 1.5 hours earlier with trimeprazine syrup $50 \mathrm{mg}$, anaesthesia was induced with thiopentone $3 \mathrm{mg} \cdot \mathrm{kg}^{-1}$ and atracurium $0.3 \mathrm{mg} \cdot \mathrm{kg}^{-1}$ to facilitate endotracheal intubation. Anaesthesia was maintained with nitrous oxide 66 per cent in oxygen and satisfactory relaxation was obtained using increments of atracurium $0.1 \mathrm{mg} \cdot \mathrm{kg}^{-1}$ to allow one to two twitches in response to train-of-four stimulation. A vaporiserfree anaesthetic machine and disposable Bain breathing circuit were used. Monitoring consisted of a Bard nerve stimulator with surface electrodes, ECG, blood pressure cuff and temperature probe. The patient was extubated in the lateral position when recovery of twitch height was confirmed at the end of the procedure. The postoperative course was uneventful.

Patients with DMD present with pelvic weakness in the first decade of life which progresses to involve the shoulder muscles, with most being confined to a wheelchair by the middle of the second decade. Fatty infiltration of skeletal muscles gives the impression of pseudohypertrophy. An obstructive cardiomyopathy is common and most develop restrictive airways disease. The resting $\mathrm{CPK}$ is usually raised ( $7830 \mathrm{IU} / \mathrm{L}$ in the patient described). Death is usual in the second decade from respiratory or cardiac failure. Slucka described four groups of ECG changes in a review of 106 cases of DMD. ${ }^{1}$ The most frequent changes, tall $R$ waves in V1 \& $Q$ waves in V4-6, were present in the patient described.

There have been several reports of malignant hyperthermia (MH) in patients with DMD. ${ }^{2-5} \mathrm{Be}-$ cause of the abnormal muscles, heat production may be low and a rise in temperature may not be detected. ${ }^{2,3,5}$ Patients with DMD are at an increased risk of $\mathrm{MH}$ and appropriate precautions should be taken. ${ }^{2,6}$ Rhabdomyolysis with grossly elevated serum CPK levels and myoglobinuria with acidosis following halothane and succinylcholine anaesthesia have been reported, ${ }^{7,8}$ including two cases of cardiac arrest. ${ }^{9}$ Indwelling arterial lines have not previously been routinely used, but facilities for arterial blood gas and electrolyte estimations should be available. $2,3,5$

It is suggested that an anaesthetic machine free of volatile agents and including a new disposable breathing circuit is used and that succinylcholine is avoided. Monitoring should include temperature probe, ECG, and a nerve stimulator. Because an acute tachycardia may precede the onset of cardiac failure in patients with DMD, atropine should be avoided. ${ }^{2}$ The absence of vagolysis with atracurium combined with the ability to allow reversal to occur without using neostigmine and atropine is a significant advantage. Atracurium, because of its unique mode of degradation to inactive fragments allows complete recovery of neuromuscular function after anaesthesia. ${ }^{10}$ These properties make atracurium the most suitable agent to use in patients with DMD who are at an increased risk of postoperative respiratory complications.

\section{F.A. Rosewarne MD}

Department of Anaesthetics

The Royal Melbourne Hospital

Victoria, 3050, Australia 


\section{REFERENCES}

1 Slucka $C$. The electrocardiogram in Duchenne progressive muscular dystrophy. Circ 1968; 38: 933-9.

2 Kelfer MH, Singer WD, Reynolds RN. Malignant hyperthermia in a child with Duchenne muscular dystrophy. Pediatr 1983; 71: 118-9.

3 Brownell AKW, Paasuke RT, Elash A et al. Malignant hyperthermia in Duchenne muscular dystrophy. Anesthesiology 1983; 58: 180-3.

4 Oka S, Igarishi Y, Takagi A, Nishida M, Sato K, Ideda $K$. Malignant hyperthermia and Duchenne muscular dystrophy: a case report. Can Anaesth Soc J 1982; 29: 146-8.

5 Linter SPK, Thomas PR, Withington PS, Hall MG. Suxamethonium associated hyperonicity and cardiac arrest in unsuspected pseudohypertropic muscular dystrophy. Br J Anaesth 1982; 54: 1331-2.

6 Rosenberg H, Heiman-Patterson T. Duchenne's muscular dystrophy and malignant hyperthermia: another waming. Anesthesiology 1983; 59: 362.

7 Miller ED, Sanders DB, Rowlingson JC, Berry FA, Susman MD, Epstein RM. Anesthesia-induced rhabdomyolysis in a patient with Duchenne's muscular dystrophy. Anesthesiology 1978; 48: 146-8.

8 Boltshauser E, Steinmann B, Meyer A, Jerusalem $F$. Anacsthesia induced rhabdomyolysis in Duchenne muscular dystrophy. $\mathrm{Br} \mathrm{J}$ Anaesth 1980; 52: 559.

9 Seay AR, Ziter FA, Thompson JA. Cardiac arrest during induction of anaesthesia in Duchenne muscular dystrophy. J Pediatr 1978; 93: 88-9.

10 Chapple DJ, Clarke JS. Pharmacological breakdown products of atracurium and related substances. Br J Anaesth 1983; 55: 11-5S.

\section{Endotracheal tube connector fracture - an avoidable hazard}

To the Editor:

I was called to see a two-year-old patient who was nasally intubated with a \#4.0 mm Portex endotracheal tube. The $15 \mathrm{~mm}$ connector had fractured at a point where the connector narrows to a cone for insertion into the polyethylene tube (Figure). The patient required hyperventilation and was therefore receiving neuromuscular blocking drugs. Careful

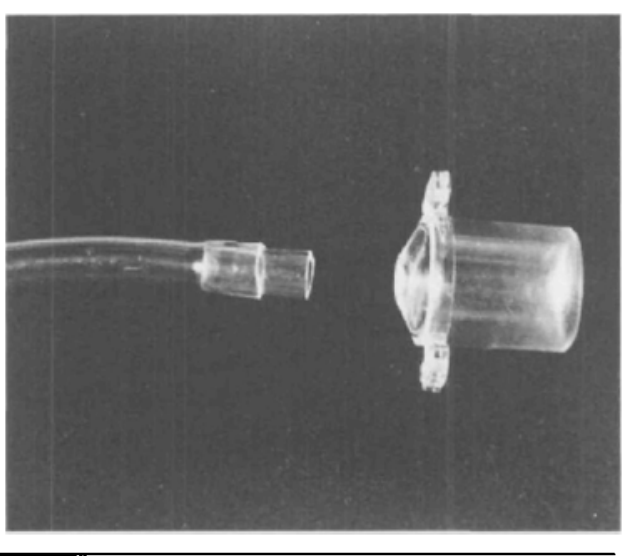

FIGURE Photograph of fractured endotracheal tube connector.

apposition of the broken connector ends enabled ventilation to continue prior to re-intubation of the child.

The cause of this breakage was initially a mystery as no unusual stresses were thought to have been placed on the connector. Since the patient was receiving neuromuscular blocking drugs, sudden head movement was not responsible. Careful examination of the tube revealed imprints of the jaws of forceps in the polyethylene tube. The endotracheal tube had been shortened two days earlier and forceps were used to aid the insertion of a new connector. Excessive stress at this time was presumably responsible for weakening of the connector. Minor stresses since that time had resulted in its ultimate breakage.

Defective tracheal tube connectors have been reported $^{1,2}$ but testing of a batch of these connectors revealed no weakness. Microscopic examination of the broken connector showed no evidence of moulding faults. The practice of cutting an endotracheal tube whilst the tube is in situ is felt therefore to be potentially hazardous. If required, re-intubation with an endotracheal tube of correct length is recommended.

\section{Nixon MB CH B FFARCS} Intensive Care Unit

Hospital for Sick Chilren Toronto, Ontario 